\title{
A Design Methodology for Learning Analytics Information Systems: Informing Learning Analytics Development with Learning Design
}

\author{
Andy Nguyen \\ University of Auckland \\ a.nguyen@auckland.ac.nz
}

\author{
Lesley Gardner \\ University of Auckland \\ 1.gardner@auckland.ac.nz
}

\author{
Don Sheridan \\ University of Auckland \\ d.sheridan@auckland.ac.nz
}

\begin{abstract}
The paper motivates, presents and demonstrates a methodology for developing and evaluating learning analytics information systems (LAIS) to support teachers as learning designers. In recent years, there has been increasing emphasis on the benefits of learning analytics to support learning and teaching. Learning analytics can inform and guide teachers in the iterative design process of improving pedagogical practices. This conceptual study proposed a design approach for learning analytics information systems which considered the alignment between learning analytics and learning design activities. The conceptualization incorporated features from both learning analytics, learning design, and design science frameworks. The proposed development approach allows for rapid development and implementation of learning analytics for teachers as designers. The study attempted to close the loop between learning analytics and learning design. In essence, this paper informs both teachers and education technologists about the interrelationship between learning design and learning analytics.
\end{abstract}

\section{Introduction}

Recent research has increasingly recognised the importance of the role of teachers as designers in education, especially in the context of TechnologyEnhanced Learning (TEL) [2, 13]. Although the idea of incorporating teaching with design-based pedagogies is not new [9, 19, 34], lately educational technologists and researchers have considered that developing best practice and effective pedagogy for TEL is the key to effective technology integration [11]. Technology integration in education is no longer an independent objective being accomplished separately from pedagogical goals, but now the means by which learning and teaching occur. Educators have used technology as a cognitive tool for evolving critical thinking and higher-order skills and this leads to the term "learning design (LD)" [11]. Learning design is the practice of creating, managing and evaluating learning activities, usually adopting technology to support design and delivery. The primary goal of learning design research has been to support the role of teachers as designers, using both technological solutions and educational theories [23].

Unfortunately, despite years of research and significant contributions to education, LD has not broadly impacted teaching practice [2, 4]. Previous studies have identified several barriers to learning design including the limitations of LD tools and LD mindset. Furthermore, TEL interventions raise challenges to the management and evaluation of learning design. TEL often involves a Virtual Learning Environment (VLE) thus it is challenging to monitor learning via traditional educational measurements such as in-class observation. In addition, digitalisation in learning and teaching has produced an immense volume of educational data that may cause information overloads in the process of learning design.

Fortunately, advances in the IT industry and specifically the recent evolution of big data technologies have enabled the automatic process of capturing, storing and analysing a massive amount of educational data. Through the application of data analytics, we can now accurately report on students' interactions with online resources. The applications of these technologies in education has coined the term "learning analytics". In previous studies on learning analytics, different practical implications have been identified as related to user behaviour and engagement modeling, predictive analysis, personalization and adaptive learning $[7,26$, $27,30,37]$.

In spite of the potential of learning analytics, some research has indicated a need to address the gap between learning analytics and learning design [1, 24, 31]. It is essential to establish common guidance on the development of learning analytics for learning design and how to implement learning analytics to competently refine and redesign learning activities. Taking into consideration the objectives, strengths, and weaknesses of learning design and learning analytics, the natural interrelationships between these two domains has led to 
increasing interest and initiation of bridging them [1, 15]. This study attempts to show a direction towards closing the loop between learning design and learning analytics. Therefore, this study adopted frameworks from both learning design and learning analytics to propose a design methodology that supports the process of designing and evaluating learning analytics information systems (LAIS). To do so, we first review the related literature and conceptual frameworks. We then propose a service-oriented approach for the design and development of learning analytics for learning design. Accordingly, we present and demonstrate the design methodology for LAIS. Finally, we discuss the research propositions, implications for practice and further research.

\section{Problem Identification: Design and Development of Learning Analytics Information Systems}

A substantial volume of literature has been published on using LA as a method to gain insights into learners and their learning [14, 30, 33]. Although the previous research has significantly contributed to the understanding in the education domain, the studies usually conducted using ad-hoc analyses to answer a specific research question, not gain information that could be used for widespread development and implementation of learning analytics information systems (LAIS).

Other studies have proposed several LAIS for practical implementation [5, 21, 32, 36]. For example, Gavriushenko, Saarela, \& Kärkkäinen [12] proposes a system architecture towards the development of an automated system for the academic advising process. This architecture allows for defining the study profiles and recommending the proper study path to the learners. An example is GLASS (Gradient's Learning Analytics System), a web-based visualisation platform for learning analytics, proposed by Leony et al. [21]. The system enables a simple workflow for creating visual graphs to represent information related to students and their learning process. The graphic presentation of information is displayed as widgets in a canvas on the visualisation dashboard. Previous studies have also highlighted the potential of using learning analytics to support learning design activities [3, 18, 25]. Nevertheless, it is now well established how learning design activities can inform the development of LAIS and how to design such systems that can effectively support learning design.

Most studies in the field of LA have developed and implemented LA for a specific application. To our knowledge, no studies have synthesised and

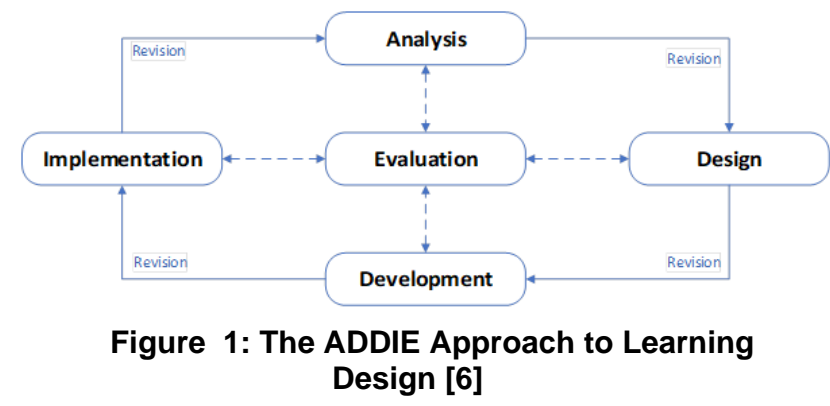

conceptualised the design methodology for LAIS. The research question for this study is as follows: How to design Learning Analytics Information Systems (LAIS) can support learning design effectively.

\section{Aligning Learning Design (LD) with Learning Analytics (LA)}

\subsection{Teachers as Designers}

In many ways, teaching can be interpreted as a design activity. Teachers achieve their instructional goals by perceiving and interpreting existing resources, analysing the classroom conditions and relevant constraints, balancing trade-offs and delivering best practice. These are also the characteristics of design, which is the acts of creating, delivering and evaluating artefacts to accomplish goals and objectives for particular users under certain constraints [19]. Furthermore, the widespread use of technologyenhanced learning (TEL) has changed the role of teachers in classrooms [2, 13]. Rather than simply giving instructions or introducing new knowledge, teachers need to plan and design learning activities as well as engage their students in learning [9]. As a result, learning design (LD) research seeks to share pedagogical methods and design to produce effective teaching practices in preparation for TEL interventions.

Educators and researchers have also conceptualised teaching as a design process and established relevant frameworks. For instance, the five-phase approach to learning design by Branch (2009), ADDIE (Analysis, Design, Development, Implementation, and Evaluation), has been widely applied in the LD community. The ADDIE process starts with the analysis phase in which teachers identify instructional problems and objectives, and relevant parameters about learners and the learning environment. In the design phase, learning designers specify learning objectives and systematically plan for relevant assessments, learning materials, and content delivery. Relevant assets and materials are developed and delivered during the development and implementation phases respectively. The final phase of the ADDIE approach is LD 


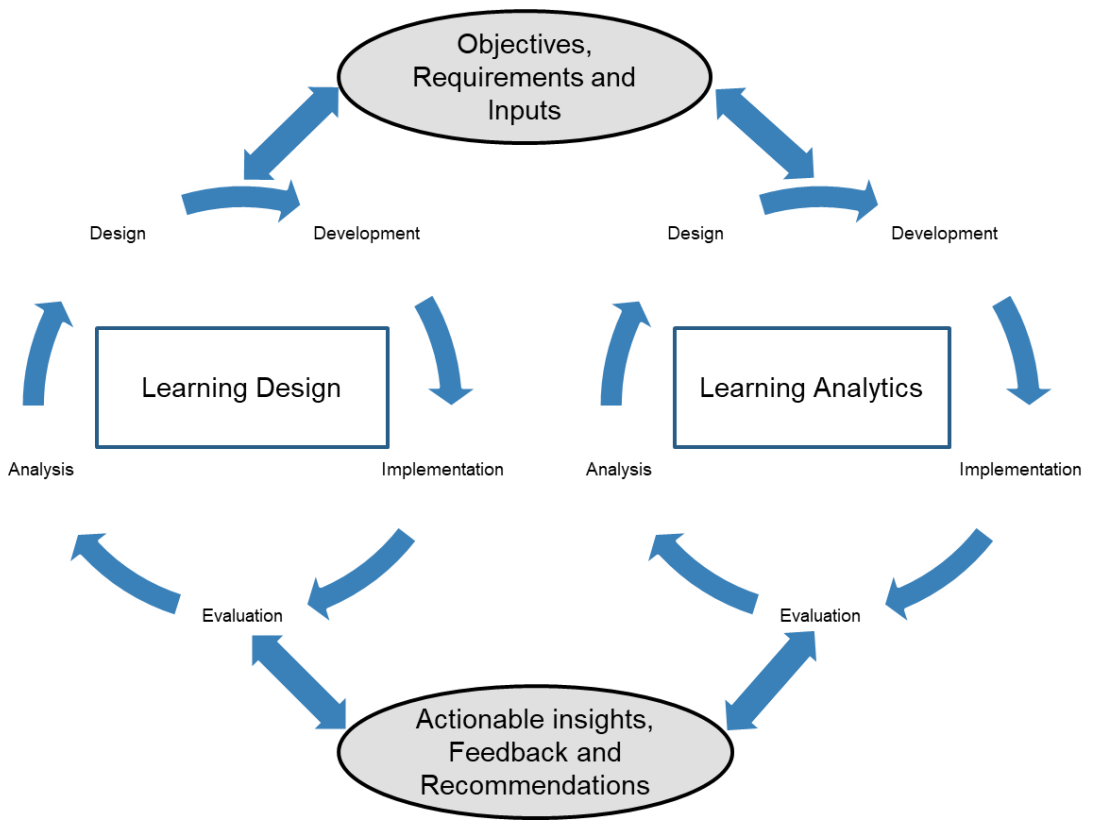

Figure 2: The Interrelationship between Learning Design and Learning Analytics

evaluation, which can be either formative or summative. While learning designers conduct a formative evaluation after each step, summative evaluation is only performed at the end of the LD process. Figure 1 shows the ADDIE Approach to Learning Design by Branch [6]. The formative evaluation is demonstrated as revisions through the ADDIE iterative process.

Similarly, Lynch \& Smith [22] proposes a learning design process based on 8 Learning Management Questions (LMQs) [39] (Figure 2).

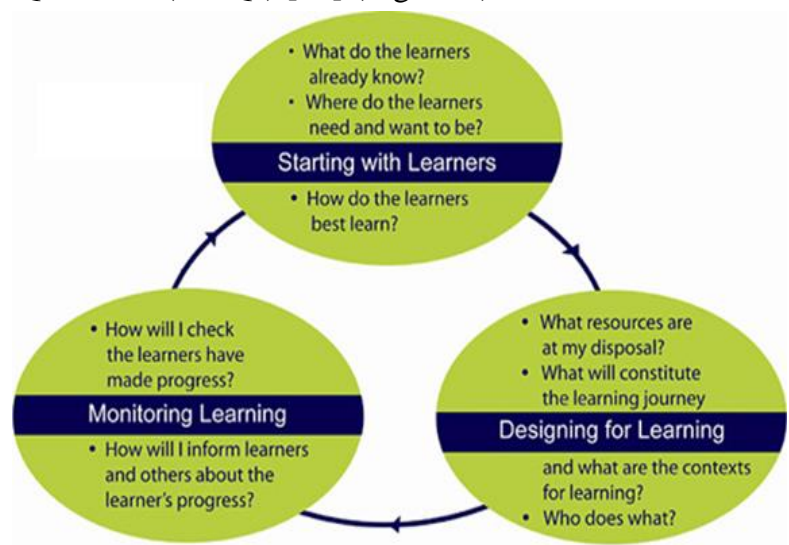

Figure 3: Learning Design Process [20]

The proposed process allows teachers to "design learning experiences that produce intended learning outcomes." The LD Process consists of three main phases: 1) Profiling, 2) Strategising and Delivery, and 3) Ascertainment and Reporting. Each phase includes a set of LMQs to guide teachers through learning design.

\subsection{Bridging the Gap between Learning Design (LD) and Learning analytics (LA)}

In general, learning analytics refers to the applications of data analytics in learning and teaching. The widely adopted definition for learning analytics is "the measurement, collection, analysis, and reporting of data about learners and their contexts, for purposes of understanding and optimizing learning and the environments in which it occurs" [35]. Learning analytics aim to process educational data to offer meaningful information related to learner profiles, learning materials, and learning context.

Learning analytics offer remarkable benefits to different educational stakeholders including lecturers and students [26]. For instance, learning analytics could update the latest information about the learning activities, and student engagement. This information could be used to construct a model of successful student behaviour [37]. Furthermore, the instructors may use the model of learning behaviour to revise learning activities and remove those activities unrelated to the course objectives.

Learning analytics can support learning design in many ways [17, 28, 31, 40]. For example, learning analytics can facilitate the evaluation of learning design, i.e., determine the appropriateness of particular instructional design in teaching [8]. During the process of learning design, teachers' intentions can be to understand the needs of their students as well as learning processes. Learning analytics can offer evidence to inform teachers on the outcome of learning design in aspects such as student engagement with learning 
materials, learning activities latency, and learning paths followed by the students $[15,18]$.

On the other hand, learning design informs the design and development of learning analytics on the objectives, contextual information, and relevant parameters. The development and implementation of learning analytics should focus on not only technology used to capture the data but also the educational context where it may be used [10]. Rather than being an end goal, analytics should act as means to provide actionable insights to educational stakeholders, including teachers [36]. In order to obtain useful LA outputs, one of the requirements is not to isolate the data analysis process from the context which it investigates [15].

Recently, some research has attempted to bridge the gap between learning design and learning analytics [3, 15, 31]. For instance, Bakharia, Corrin, et al. [3] have proposed a design pattern to mediate learning design and learning analytics. This framework clearly described the dimensions and types of learning analytics and how to apply them in supporting learning design.

The literature review has shown a legitimate relationship between learning design and learning analytics. Based on the above literature review, we have illustrated the interrelationship between learning design and learning analytics in Figure 3 below. Overall, the two closed-loop design processes learning design and learning analytics are interrelated and interact with each other. The outputs of one process inform actionable insights and acts as inputs for the other process.
Previous research has demonstrated how learning design has led the development of learning analytics and how the implementation of learning analytics has helped learning design activities [15, 31]. Nevertheless, much attention has been paid to inform learning design with learning analytics outcomes while what is less clear is how learning analytics tools can be rapidly developed based on the needs of learning designers. As a result, this study attempts to close the loop between learning design and learning analytics.

\section{A Methodology for Designing and Developing of Learning Analytics Information Systems for Learning Design}

The design methodology for LAIS was designed by integrating theories and frameworks from different disciplines namely learning analytics $[10,26]$, learning design [6, 22], and design science in information systems [16, 29]. Through the review of related literature, the theories and frameworks were selected based on the purpose of the design methodology for LAIS and from the well-known publications in each research area. Regarding the design and development activities, Service-Oriented Architecture (SOA) has been a popular approach in system design because of its high flexibility and extensibility. The SOA system consists of multiple discrete components providing a set of defined functionalities. A service presents each unit of functionality that can operate and be updated

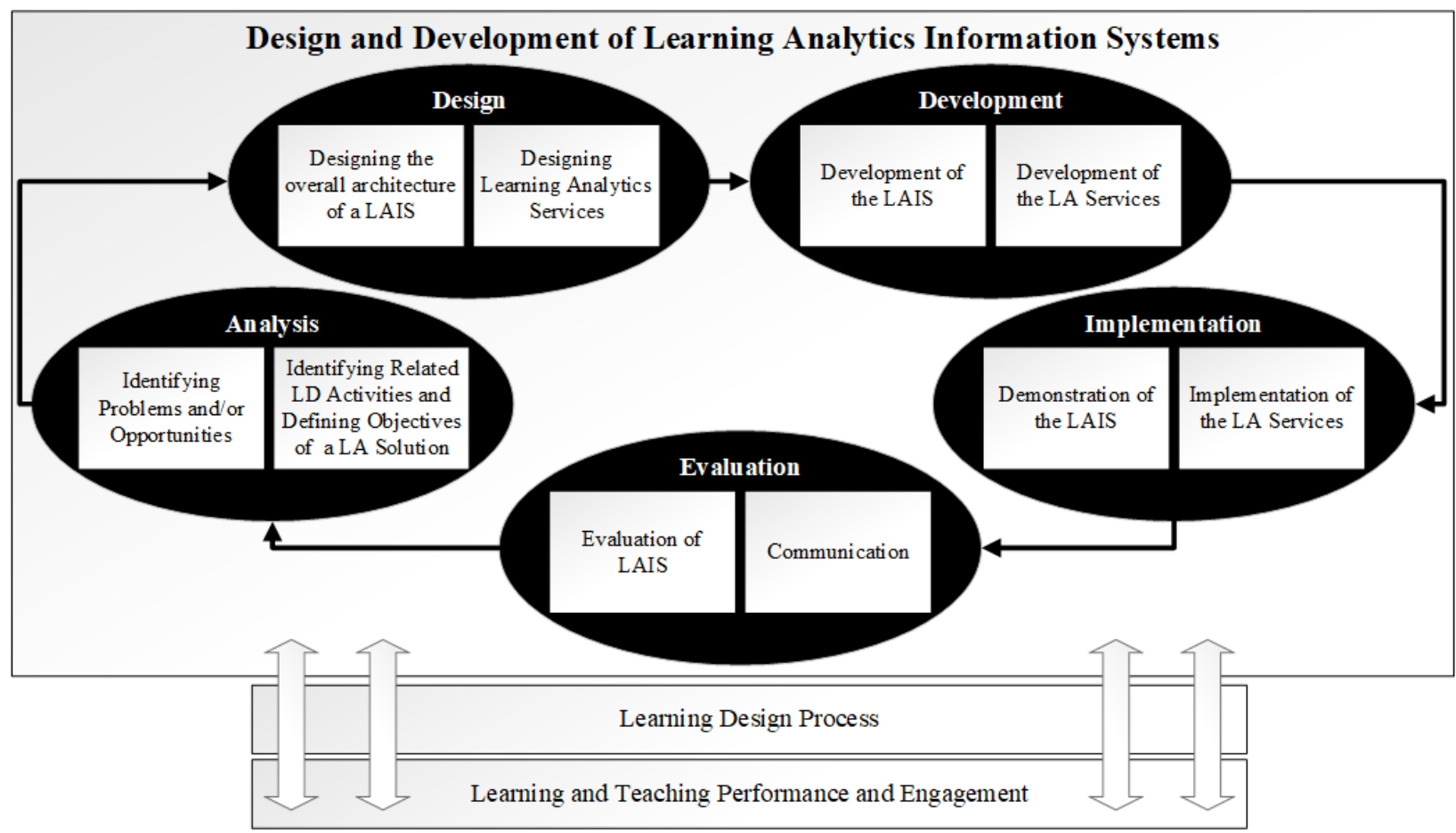

Figure 4: Learning Analytics Information Systems (LAIS) Design Methodology 
independently. We adapt the SOA approach in our LAIS design methodology for its robustness. The proposed methodology consists of five main activities namely: Analysis, Design, Development, Implementation, and Evaluation (as shown in Figure 4).

\subsection{Analysis}

This first activity involves the identification of research problems or opportunities, determining related learning design activities and defining objectives of a learning analytics solution. Since the problem definition will be used to design an artifact that can provide an effective solution [29], it is useful to atomise the problem practically and conceptually. The identification of the research problems or opportunities for LAIS should emerge from the observation and evaluation of the learning design process and learning and teaching practice. Furthermore, it should be informed by the relevant literature in the research domain.

The related learning design activities and beneficial phases should be defined for establishing effective objectives of a learning analytics solution. Figure 5 shows a template for the alignment network between learning analytics services and learning design activities. This step will provide a clear focus for the design and development of LAIS.

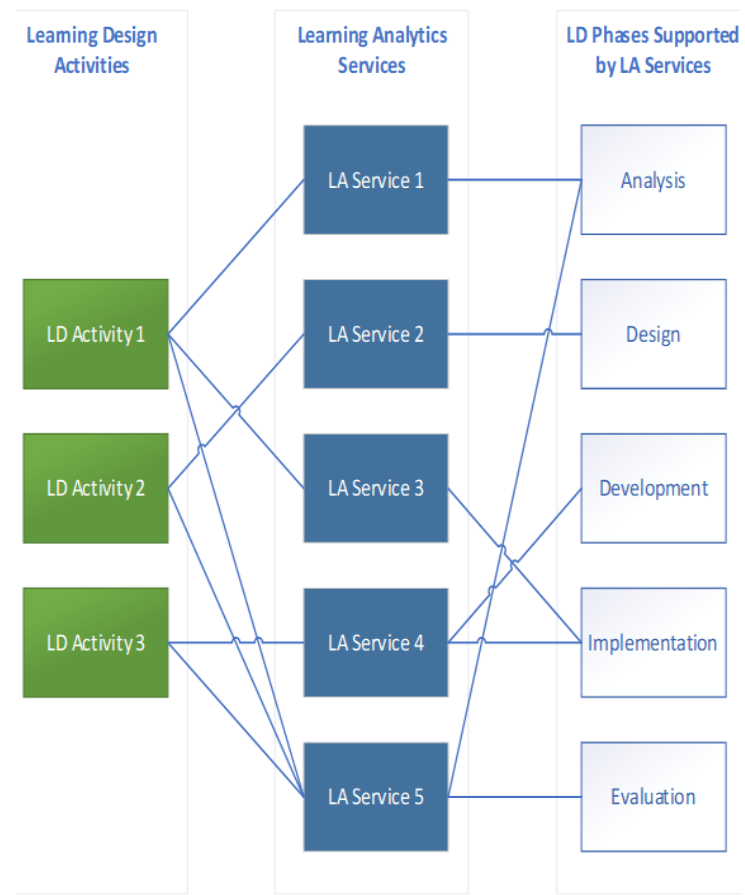

Figure 5: Alignment Network between Learning Analytics Services and Learning Design Activities

\subsection{Design}

By adopting the SOA approach, the design of a LAIS following our approach allows for the parallel development and implementation of different learning analytics service at the same time while maintaining comprehensive interoperability between the services. Furthermore, the architecture needs to support the flexibility to interoperate with different educational systems. The design activity includes the design of the overall system architecture and the design of specific learning analytics services. Nevertheless, by using a single overall architecture, researchers can design different learning analytics services in multiple studies.

Figure 6 demonstrates an overall architecture for learning analytics information systems (LAIS). The LAIS includes three main components: 1) Data pipeline, 2) Learning analytics services, and 3) Reporting and response services.

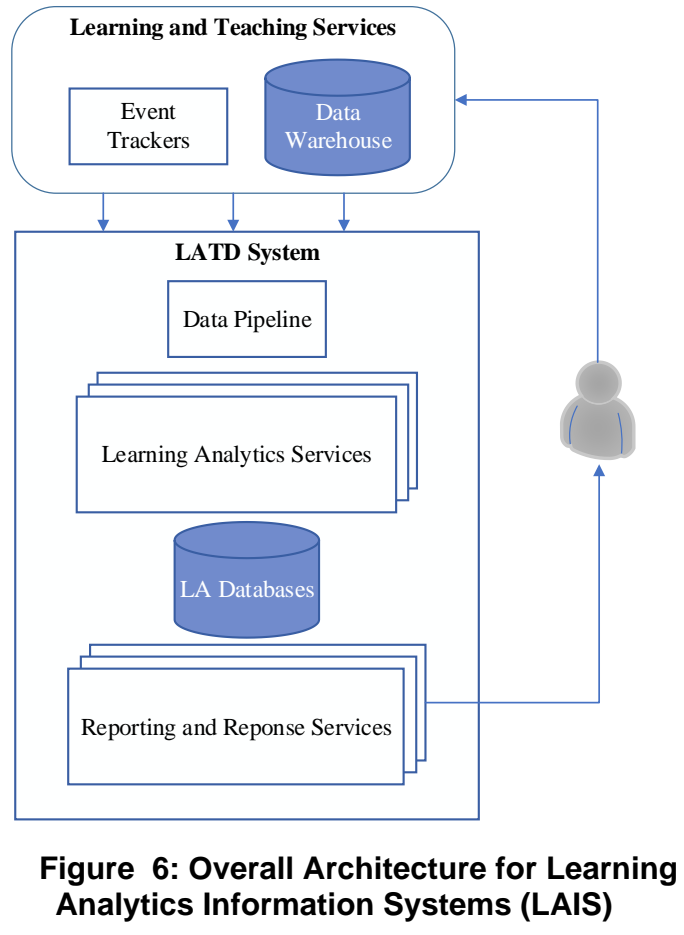

Data pipeline collects, cleans and digests both dynamic and static data. Dynamic data such as browser events are collected from event trackers embedded in the learning and teaching systems. Static data, such as course content or personal profile, are gathered from the institutional data warehouse. Learning analytics services consist of different applications addressing the needs of teachers during the learning design process. The development process of learning analytics services should consider both the needs of teachers as learning designers and learning analytics capabilities. Previous research has recognized various applications of learning 
analytics in supporting learning and teaching. For instance, Nguyen et al. [26] have established a multilayered taxonomy of learning analytics applications. Learning analytics developers may incorporate the applications of learning analytics with specific user requirements to create effective LAIS. Figure 7 demonstrates the abstraction of interactions between la services and learning and teaching systems which can be applied for the design of LA services.

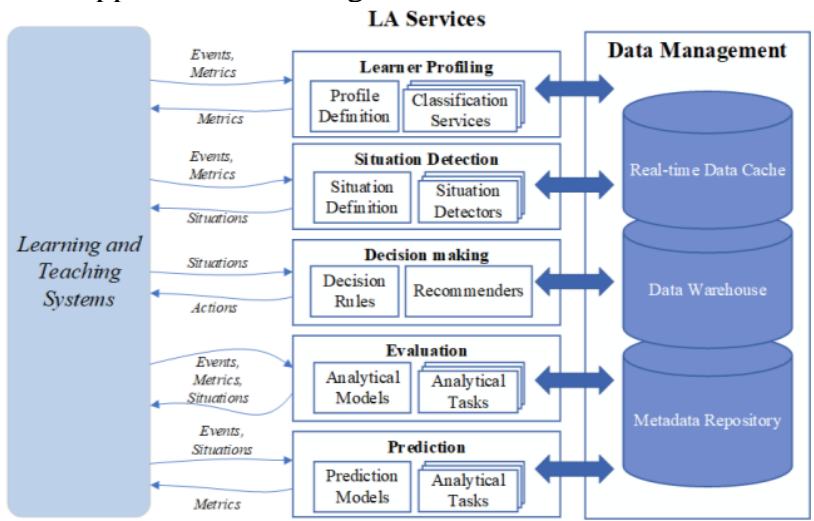

Figure 8: Abstraction of Interactions between LA Services and Learning and Teaching Systems

The proposed LAIS architecture allows the parallel development and implementation of different learning analytics at the same time while maintaining comprehensive interoperability between the services. Furthermore, the architecture also supports the flexibility to interoperate with different educational systems.

\subsection{Development}

In this activity, the researchers start building the system and learning analytics services based on the proposed design. The objectives of the learning analytics solution, alignment between LA services and learning design activities and phases, and system design established in previous activities should be reflected through the development of the new LAIS as a research artefact.

\subsection{Implementation}

To demonstrate the effectiveness of using the LAIS to support learning design in practice and to solve one or more instances of the identified problem, the system needs to be implemented in a case study or field study. The implementation of LAIS may require procedures for informing the users, e.g. teachers as learning designers, about how to use the system to support their learning design activities.

\subsection{Evaluation}

The evaluation of LAIS involves observing and measuring how well the system supports the learning design process and solves an instance of the problem. This activity can be conducted using any appropriate empirical evidence and data analysis methods. The evidence of LAIS effectiveness is obtained through feedback from the learning and teaching activities. The evaluation of learning analytics services based on learning design outcomes provides useful feedback for the improvement of existing LAIS, and development and implementation of future learning analytics services. These feedback loops are essential to close the loop between learning design and learning analytics as demonstrated in Figure 8. LAIS enables accelerated learning analytics development informed by the needs of learning design.

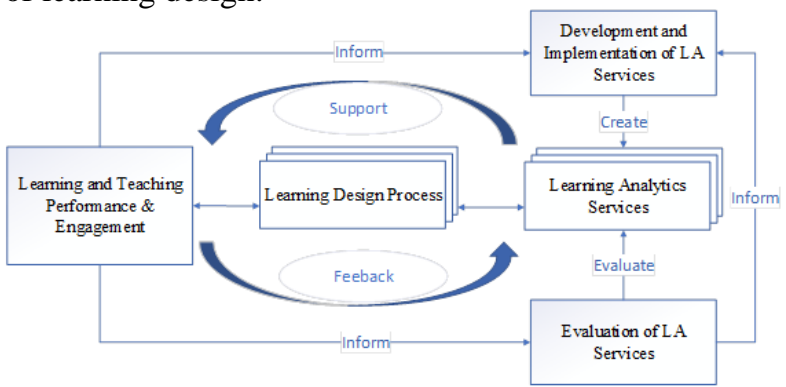

Figure 7: Closing the Loop between Learning Design and Learning Analytics

Furthermore, as part of the evaluation, the researchers also need to communicate the design and development with the research communities. The communication involves writing, presenting, and publishing the design to appropriate academic conferences and journals.

\section{Demonstration of LAIS Design Methodology}

For demonstration purposes, this section illustrates the application of the proposed design method for LAIS to develop a LA service that provides useful information about how university students interact with lecture theatre recordings (LTR).

Analysis: Lecture Theatre Recordings (LTR) have emerged as a powerful tool for teaching and learning. Evidence suggests that LTR have many advantages in higher education including the flexibility to access learning content on demand [20, 38, 41]. Leadbeater et al. [20] noted this high usage of LTR in their evaluation of the use and impact of lecture recording in undergraduates. The information about student engagement can also aid lecturers to identify instructional problems and improve lecture content. As 
learning is a complex process involving the interactions between the learners and learning materials facilitated by the lecturers and institutional resources, the quality of instruction and provided resources could influence the learning outcome indirectly. However, prior research suffered from a granular form of learning analytics which amounted to access counts and survey data. The system did not record, for example, how much time the students actually spent on the lecture recordings. Furthermore, students' positive perception of LTRs may be influenced by the new flexibility to access learning content for a baseline of no access at all. Noticeably missing from the current literature, even now, is a detailed analysis of the use of LTR based on objective evidence. This indicates a need to apply a lecture theatre recordings (LTR) evaluation service at the university.

Figure 9 illustrates the position of the lecture theatre recordings (LTR) evaluation service in the alignment network between learning analytics services and learning design activities. The LTR evaluation service may allow evaluating and analysing lecture content in aspects of online learning via lecture recordings. The service provides the lecturers with evidence of the impact of current lecture content design, and these actionable insights are useful for future construction of lecture content.

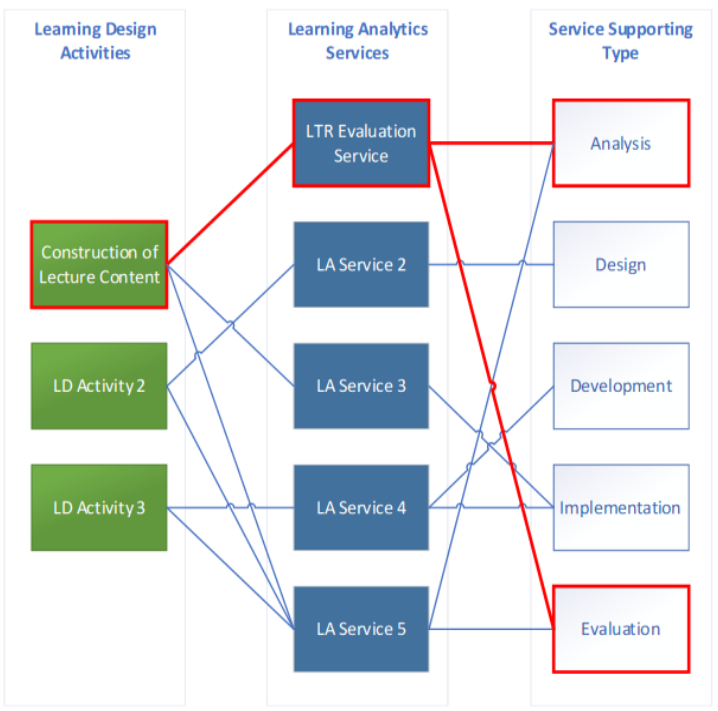

Figure 9: An Example of Alignment Network between LA Services and LD Activities

Design: Based on the overall architecture for LAIS (Figure 6), a detailed technical design for the LAIS has been constructed as shown in Appendix 1. Using the proposed abstraction of interactions between la services and learning and teaching systems (Figure 7) the demonstrated service was designed as shown in Appendix 2.
Development: A prototype of LAIS has been developed based on the prior analysis and design (Appendix 3).

Implementation: The prototype was implemented at the University of A, for a case-study based evaluation. The learning analytics system was applied in four undergraduate courses with a total of 1,173 enrolments. They consisted of one large-size first-year course $(n=966)$, and three second-year courses $(n=207)$.

Evaluation: The interview explored the lecturers' practice on the system and its perceived usefulness. All the lecturers reported that the implemented system is beneficial and supportive in monitoring student engagement with learning through the semester. The analytics information helped them to identify potentially problematic parts of the lecture content. For instance, if students experienced difficulties due to poor sound quality and missed out a piece of essential information, the lecturer may detect a problem due to the unusual activities of students at that point in the video. The lecturer may revise that specific piece of information in the following lecture.

Moreover, the lecturers also reported that the system allows them to observe the content most often replayed by the students. They commented that this insight would help the decision making in designing the course for the following semester. In particular, the lecturers observed that students spent more time in gap-fill exercises, which learners have to fill in missing words removed from a text, than the rest of the lecture recordings. As a result, they aimed to use these kinds of exercises to emphasize essential pieces of knowledge.

Nevertheless, the lecturers noted that the lack of granularity regarding analytics visualisation negatively influenced both perceived usability and usefulness. It is a challenge to provide enough information effectively without causing information overload. Learning analytics practitioners should carefully consider the information density and the design to avoid unclear information which may trigger misinterpretation. Furthermore, the extra working hours should be needed to adopt and use a new application while maintaining their usual roles and responsibilities. Our findings indicate that future learning analytics should also consider the ease of use for the users, the appropriateness and flexibility of delivered information density. The implementation of learning analytics should be comprehensively deliberated and supported by all levels of stakeholders at the institution.

\section{Research propositions}

The proposed approach and methodology for developing LAIS may lead to a number of streams of research that could be pursued. In essence, this section 
depicts research propositions focusing on the proposed benefits for the stakeholders that a LAIS system, based on this framework, could provide. Particularly, research in this stream could be guided by research propositions specific to teachers as learning designers, software developers, and learners.

Proposition 1: Teachers as learning designers will be more satisfied using a LAIS developed based on the proposed LAIS design methodology than a traditional learning analytics system because of greater support for the learning design activities. In terms of tracking learner progress, the LAIS will produce insights not only about the class' progress as a whole but also smaller groups with similar characteristics for analysis. By using this information, the teacher will analyse the needs of each group of students as well as the common needs of the class. Hence, the teacher will design appropriate learning activities in accordance with the student needs. The recommender module of LAIS will greatly benefit the development and implementation phases of learning design. The system will also enable the teacher to dynamically monitor the learning progress, thus offer feedback about the effectiveness of the learning design implementation. For instance, in terms of identification of learning design delivery problems, the LAIS will generate information about how particular instructional material is being used by students. This information will be further analysed by the statistical model to identify areas where learners are having problems with the learning design activities.

Proposition 2: Educational software developers will be able to faster design and develop more effective LAIS using the proposed methodology. The LAIS framework will serve as a guideline for further development and implementation of learning analytics services in higher education. The proposed serviceoriented approach will enable educational developers to effectively address the needs of teachers and learners. LAIS will guide designers and developers to create and evaluate user-centred learning analytics services to support learning and teaching.

Proposition 3: Learners will be more satisfied using a LAIS system rather than a traditional learning system with learning analytics capabilities. Rather than providing generic descriptive or prescriptive statistics like common learning analytics tools, LAIS provides more detailed feedback about the learning progress in relation to the learning design and learning outcomes. LAIS enables the learners to evaluate their performance in accordance with the designed tasks.

\section{Conclusion}

The proposed design method for LAIS acts as a guideline for further development and implementation of learning analytics to support learning design. More broadly, this study also informs commercial interests, software developers, and engineers about the LA services and functionalities that the teachers appreciate to support educational design. Specifically, the abstraction of interactions between LA services and learning and teaching systems may aid software developers and engineers new to LA technology and its relationship with learning design.

The proposed design methodology for LAIS adopts the Services Oriented Architecture (SOA) to design an underlying infrastructure to handle multiple independent LA services. The "plug-and-play" capability of LA services supports the development of high-performance LAIS with great interoperability, extensibility, and reusability. The utility of LAIS framework lies in its ability to direct rapid development and implementation of learning analytics for teachers as learning designers. Further research could adopt and refine this method to produce a unified standard for LA development to enhance the collaboration among developers and researchers.

Considerably additional development and evaluation will need to be conducted to examine LAIS architecture comprehensively. In addition, more conceptual and empirical work should be conducted to improve the approach and consider the feedback loops between learning analytics and different stakeholders including learning designers, system developers, and learners.

\section{References}

[1] Alhadad, S.S.J., K. Thompson, S. Knight, M. Lewis, and J.M. Lodge, "Analytics-enabled teaching as design", Proceedings of the 8th International Conference on Learning Analytics and Knowledge $L A K$ '18, ACM Press (2018), 427-435.

[2] Asensio-Pérez, J.I., Y. Dimitriadis, F. Pozzi, et al., "Towards teaching as design: Exploring the interplay between full-lifecycle learning design tooling and teacher professional development", Computers \& Education 114, 2017, pp. 92-116.

[3] Bakharia, A., L. Corrin, P. de Barba, et al., "A conceptual framework linking learning design with learning analytics", Proceedings of the 6th International Conference on Learning Analytics and Knowledge, ACM Press (2016), 329-338.

[4] Bennett, S., S. Agostinho, and L. Lockyer, "The process of designing for learning: understanding university teachers' design work", Educational Technology Research and Development 65(1), 2017, pp. 125-145.

[5] Bodily, R., T.K. Ikahihifo, B. Mackley, and C.R. Graham, "The design, development, and 
implementation of student-facing learning analytics dashboards", Journal of Computing in Higher Education 30(3), 2018, pp. 572-598.

[6] Branch, R.M., Instructional Design: The ADDIE Approach, Springer US, Boston, MA, 2009.

[7] Brown, M., "Learning analytics: Moving from concept to practice", EDUCAUSE Review, 2012, pp. 15 .

[8] Chatti, M.A., A.L. Dyckhoff, U. Schroeder, and H. Thüs, "A reference model for learning analytics", International Journal of Technology Enhanced Learning 4(5/6), 2012, pp. 318-331.

[9] Conole, G., and K. Fill, "A learning design toolkit to create pedagogically effective learning activities", Journal of Interactive Media in Education 2005(1), 2005, pp. 9.

[10] Dawson, S., D. Gašević, and G. Siemens, "Let's not forget: Learning analytics are about learning", TechTrends, 2015.

[11] Ertmer, P.A., and A. Ottenbreit-Leftwich, "Removing obstacles to the pedagogical changes required by Jonassen's vision of authentic technologyenabled learning", Computers \& Education 64, 2013, pp. 175-182.

[12] Gavriushenko, M., M. Saarela, and T. Kärkkäinen, "Towards evidence-based academic advising using learning analytics", International Conference on Computer Supported Education, Springer, Cham (2017), 44-65.

[13] Goodyear, P., and Y. Dimitriadis, "In medias res: Reframing design for learning", Research in Learning Technology 21(0), 2013.

[14] Greller, W., and H. Drachsler, "Translating learning into numbers: A generic framework for learning analytics", Educational technology \& society 15(3), 2012, pp. 42-57.

[15] Hernández-Leo, D., M.J. Rodriguez Triana, P.S. Inventado, and Y. Mor, "Preface: Connecting Learning Design and Learning Analytics", Interaction Design and Architecture(s) Journal - IxD\&amp;A 33, 2017, pp. 3-8.

[16] Hevner, A.R., S.T. March, J. Park, and S. Ram, "Design science in information systems research", MIS quarterly 28(1), 2004, pp. 75-105.

[17] Howell, J.A., L.D. Roberts, and V.O. Mancini, "Learning analytics messages: Impact of grade, sender, comparative information and message style on student affect and academic resilience", Computers in Human Behavior 89, 2018, pp. 8-15.

[18] Ifenthaler, D., D. Gibson, and E. Dobozy, "Informing learning design through analytics: Applying network graph analysis", Australasian Journal of Educational Technology 34(2), 2018.

[19] Jordan, M.E., "Teaching as designing: Preparing pre-service teachers for adaptive teaching",
Theory Into Practice 55(3), 2016, pp. 197-206.

[20] Leadbeater, W., T. Shuttleworth, J. Couperthwaite, and K.P. Nightingale, "Evaluating the use and impact of lecture recording in undergraduates: Evidence for distinct approaches by different groups of students", Computers \& Education 61, 2013, pp. 185192.

[21] Leony, D., A. Pardo, L. de la Fuente Valentín, D.S. de Castro, and C.D. Kloos, "GLASS: A learning analytics visualization tool", Proceedings of the 2nd International Conference on Learning Analytics and Knowledge, ACM (2012), 162-163.

[22] Lynch, D.E., and R. Smith, "The learning management design process", In D.E. Lynch and R. Smith, eds., The Rise of the Learning Manager. Pearson Education Australia, French's Forest NSW, 2006, 5367.

[23] Maina, M., B. Craft, and Y. Mor, eds., The art \& science of learning design, SensePublishers, Rotterdam, 2015.

[24] Mangaroska, K., and M. Giannakos, "Learning analytics for learning design: Towards evidence-driven decisions to enhance learning", In 2017, 428-433.

[25] Mor, Y., R. Ferguson, and B. Wasson, "Learning design, teacher inquiry into student learning and learning analytics: A call for action", British Journal of Educational, 2015.

[26] Nguyen, A., L. Gardner, and D. Sheridan, "A multi-layered taxonomy of learning analytics applications", Pacific Asia Conference on Information Systems (PACIS) 2017 Proceedings, (2017), 54.

[27] Nguyen, A., L. Gardner, and D. Sheridan, "Building an ontology of learning analytics", Pacific Asia Conference on Information Systems (PACIS) 2018 Proceedings, (2018).

[28] Nistor, N., and Á. Hernández-Garcíac, "What types of data are used in learning analytics? An overview of six cases", Computers in Human Behavior 89, 2018, pp. 335-338.

[29] Peffers, K., T. Tuunanen, and M.A. Rothenberger, "A design science research methodology for information systems research", Journal of Management Information System, 2007.

[30] Peña-Ayala, A., "Learning analytics: A glance of evolution, status, and trends according to a proposed taxonomy", Wiley Interdisciplinary Reviews: Data Mining and Knowledge Discovery 8(3), 2018, pp. e1243.

[31] Persico, D., and F. Pozzi, "Informing learning design with learning analytics to improve teacher inquiry", British journal of educational technology 46(2), 2015, pp. 230-248.

[32] Ruiz, J., H. Díaz, and J. Ruipérez-Valiente, "Towards the development of a learning analytics extension in open edX", Proceedings of the, 2014. 
[33] Saarela, M., and T. Kärkkäinen, "Knowledge discovery from the programme for international student assessment", In Learning Analytics: Fundaments, Applications, and Trends. Springer, Cham, 2017, 229267.

[34] Schön, D.A., Educating the reflective practitioner: Toward a new design for teaching and learning in the professions, Jossey-Bass, 1987.

[35] Siemens, G., "Learning analytics: The emergence of a discipline", American Behavioral Scientist, 2013, pp. 0002764213498851.

[36] Siemens, G., D. Gasevic, C. Haythornthwaite, et al., Open Learning Analytics: An integrated \& modularized platform, 2014.

[37] Siemens, G., and P. Long, "Penetrating the fog: Analytics in learning and education", EDUCAUSE Review 46(5), 2011, pp. 30.
[38] Wieling, M., and W. Hofman, "The impact of online video lecture recordings and automated feedback on student performance", Computers \& Education, 2010.

[39] Wiggins, G.P., and J. McTighe, Understanding by design, Association for Supervision and Curriculum Development(ASCD), Alexandria, Virginia, USA, 2005.

[40] Zhang, J., X. Zhang, S. Jiang, P. Ordóñez de Pablos, and Y. Sun, "Mapping the study of learning analytics in higher education", Behaviour \& Information Technology 37(10-11), 2018, pp. 11421155.

[41] Zupancic, B., and H. Horz, "Lecture recording and its use in a traditional university course", $A C M$ SIGCSE Bulletin, 2002.

\section{Appendices}

\section{Appendix 1: Technical Architecture of the Demonstrated LAIS}

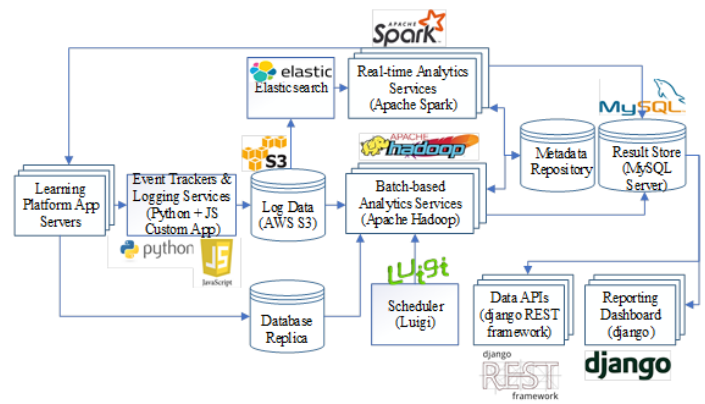

Appendix 2: Design of the Demonstrated LA Service

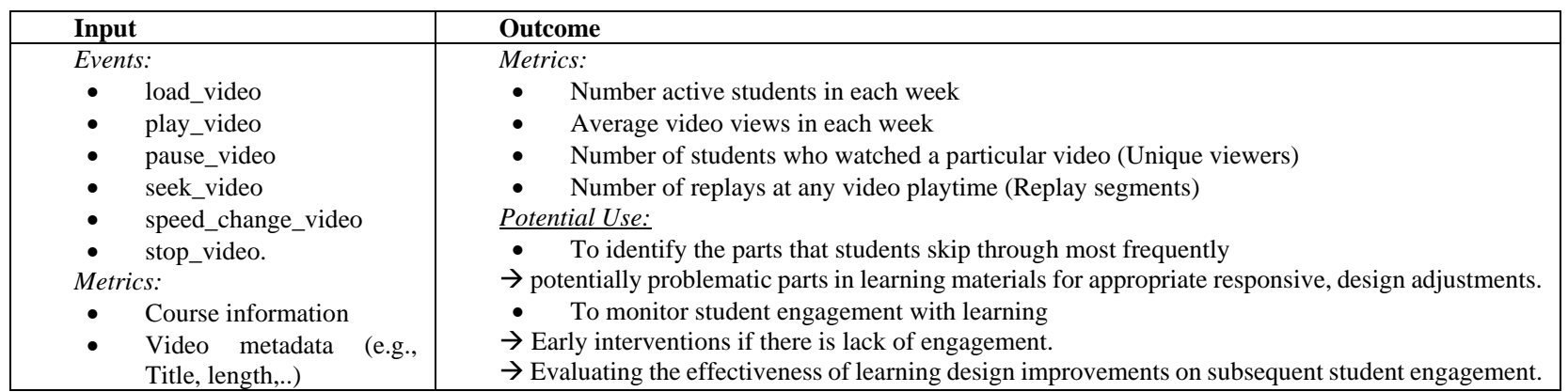

Appendix 3: User-interface (UI) of the Demonstrated LAIS

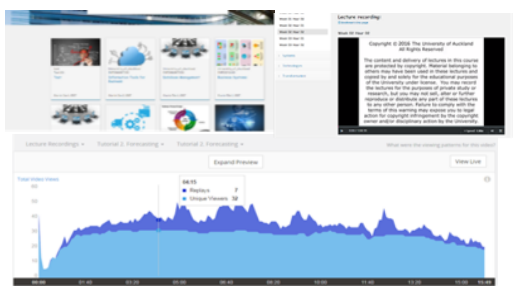

